\title{
Dynamic of Indonesian Teacher Distribution Policies Implementation at Regional Level
}

\author{
Mila Novita \\ Policy Analyst at Ministry Education and Culture \\ Indonesia \\ Chandra Wijaya \\ Professor at Faculty of Administrative Science \\ University of Indonesia \\ Andreo Wahyudi Atmoko \\ Lecture at Faculty of Administrative Science \\ University of Indonesia
}

\begin{abstract}
Indonesia education decentralization makes teacher management and distribution became regional governments responsibility. Current teacher distribution policy instrument is insufficient to distribute teachers equally. Teacher surplus in urban areas and lack in remote areas. The unequal teacher distribution indicates that the teacher distribution policy implementation does not run as planned. This study aims to understand more deeply how dynamics of the teacher distribution policies implementation in regional level in the education decentralisation sphere. The dynamic of model implementing teacher distribution policies in regional level has budget constraints, information distortion, personal interests and sectoral egos of actors and regional governments. Furthermore, the dynamic model does not fully follow feedback relationship. A relationship from organisational context to policy design is found, whereas no reverse relationship exists. The teacher distribution policy can reach the objectives rapidly by giving attention to the harmony between policy design and improvement in organisational element capacity.
\end{abstract}

Keyword: public policy, implementation, education, teacher, decentralisation, system dynamics

\section{Introduction}

Decentralization of education makes teacher management became regional governments responsibility (Chang et al.2014). Central government has a role in determining the policies, standards and supporting regulations. The central government issued a teacher management and distribution policy through a set of policy instruments available through teacher workload regulations and minimum service standards (AUSAID-KINERJA, 2014). Another instruments were the Joint Degree of 5 Ministry (2011) which was regulating teacher equity more technically (ICW, 2015). These various instruments could use by regional governments to implement teacher distribution policy.

Although various rules regarding the teacher structuring and distribution policy are available, regional government still encounter problems in the distribution of teachers. There was a difference between data and field facts. Indonesia teacher reform makes teachers become one of the financially promising professions in effect to increasing number of teacher. As a result, Indonesia has a student-teacher ratio became 1:15 that is equal to that of developed countries (Chang et al.2014). But in field showed there was over of teachers in certain school, while teacher in other school was lack. Teacher oversupply occurs in many urban areas and teacher shortages occur in rural and remote areas. (Samarraiet al. 2012, AUSAID-KINERJA, 2014; Hutagalung, 2014;).The unequal teacher distribution indicates that the teacher distribution policy implementation was not working properly in the regional level.

This study aims to understand more deeply how dynamics of the teacher distribution policies implementation in regional level in the education decentralisation sphere. Two theories, namely, policy implementation and dynamic system, are used in the current study. Policy implementation is one of stage in the policy process (Dye, 2013). Policy implementation is the carrying out of a basic policy decision in the form of laws or government regulations (Smith, 1973; Sabatier and Mazmanian, 1980). The implementation of these policy decisions enables policy instruments to achieve policy objectives. Therefore, if the implementation goes well, then the objectives of the policy will be achieved. Policy implementation analysis can be seen from three aspects of actors, policy design, and organization (Gogglin, 1986; Honig, 2006; Akiba, 2017). Akiba (2013) provides additional insights in which the three aspect have feedback relationship. Systems thinking approaches being choice because of policy implementation complexity and feedback relationship. 


\section{Literature Review}

\subsection{Dynamic System}

Maani and Cavana (2000; p.7) defined system thinking as an alternative method of thinking that is suitable for understanding complexity and change. System thinking is also a discipline to understand change and complexity through learning about the dynamics of causality and effects on time. Dynamic system is a method of system thinking in the hard system category and defines the model as a representation of the real world. The model can be in various forms, such as physical, analogue, digital (computer) and mathematics. The philosophy is for the dynamic system to emphasise the model structure, and the process within that structure assumes that this way can best characterise the dynamic behaviour in the real world. Dynamic system aims to provide managers with an understanding of the structure of complex systems; accordingly, they can intervene to ensure behaviour that fits with their goals (Flood and Jackson, 1991; Jackson, 2003). The output of the dynamic system is a model that represents a decision structure, information flow and the generated results. The output is generally used to provide an understanding of the relationship of the problem in the system for a decision experiment (Atmoko, 2009).

\subsection{Policy Implementation Model}

Gogglin (1986) observed the implementation of policies in three dimensions: (1) form and content of policies, (2) organisational capacity that is responsible for the implementation of the program and (3) qualifications of responsible actors for implementation. The viewpoint was continued by Honig (2006) and Akiba (2013, 2017), who explored the three dimensions that influence the implementation of education policies: policy design, actors and organisational contexts. They also demonstrated the interaction of the three dimensions for the first time. The interaction was specifically presented by Akiba (2013). Specifically, the three subjects are interacting with one another and collectively influence the implementation of teacher reform. The role of the three main elements in implementing policies has been identified in literature, but the interaction mechanism and the influence of these elements on reform implementation and outcome are unknown.

\subsection{Policy Implementation Dimension}

Akiba (2013) suggested that three dimensions, namely, policy design, actors and organisational contexts, can be used to analyse the implementation of teacher governance.

\subsubsection{Policy Design}

The policy design is the option that the government can implement to achieve the objectives of the policies and the outcomes of the programs (Ewalt and Jenning, 2004; Horn and Meter, 1975; Akiba, 2013; Honig, 2006; Sabatier and Mazmanian, 1983). The policy design can be developed from the standards and objectives of the policy (Horn and Meter, 1975; Edward III; 1980), ambiguity of the goal, instrument of the policy (Matland, 1995) and the compatibility of the policy with field condition (Hill and Hupe, 2002).

The two observed variables in the dimensions of policy design are clarity and consistency. The clarity of the design should be prioritised to ensure the success of its implementation for avoiding the above-mentioned situation (Matland, 1995; Akiba, 2013; Edward III, 1980; Sabatier and Mazmanian, 1983, Horn and Meters; 1975). The consistency is the extent of coherence and alignment of policies that are interconnected and reinforced with one another to guarantee that the implementer obtains the same information about the whole policy direction. (Ewalt and Jenning,2004; Edward III, 1980; Polikoff, 2012; Hoebink, 2004).

\subsubsection{Actor}

The role of actors in policy implementation theory has been discussed in terms of communication and dispositions (Horn and Meter, 1980; Edward III, 1980; Hill and Hupe, 2002; Matland; 1995). The actors involved in the policy process, particularly policy implementation, are multiple actors. The sphere policy with multiple actors presents four variables in the actor dimensions: coordination, communication, commitment and involvement (Akiba, 2013; Sabatier and Mazmanian, 1983; Allen, 2009; Pandayand Jamil, 2010; Leite and Buainain, 2013).

Coordination is highly needed in reform because changes and reforms in the public sphere increase complexity in the public sector and thus result in considerable uncertainty (Leite and Buainain, 2013). Subsequently, communication lines between actors or organisations should be established to avoid differences in acceptance and interpretation of policies. Moreover, the accuracy and consistency or similarity of information needed to obtain the same response or reception in interpreting the policy should be guaranteed (Edward III, 1980; Horn and Meter, 1979). The involvement of multiple actors in the policy process, particularly those of same interests, causes a slight resistance from actors to policy (Akiba, 2013; Croll et al, 1994; Cline, 2013; Sultana, 2008). 
The commitment of the actors in the implementation public is carried out through the selection of appropriate strategies to achieve policy objectives (Horn and Meter, 1979; Sabatier and Mazmanian, 1983; Ewalt and Jenning, 2004; Allen, 2009).

\subsubsection{Organisation}

The organisation acts as means and efforts in implementing policies. The discussion on the organisation dimensions comprises characteristics of the implementing agencies and capacity of organisations (Horn and Meter, 1979; Sabatier and Mazmanian, 1983; Akiba, 2013). The capacities include resources available (as quality and quantity) from organisational institutions of policy actor basis, structure and relationship pattern of organisations and culture and norms of organisations (Horn and Meter, 1975; Akiba, 2013; Edward III, 1980; Cline, 2013; Sabatier andMazmanian,1983; Pandayand Jamil, 2010). The ability to manage these resources increases the opportunity to achieve policy goals (Cline, 2013).

The research framework is compiled using the Akiba model with modification based on the analysis of the other literature described earlier. Additional discussion in the realm of dimensions is as follows: deepening the design dimension in terms of consistency and clarity; the actor dimension in terms of commitment, involvement, communication and coordination; and the organisational context dimension in terms of capacity. On the basis of the explanation mentioned above, the research can be described as in Figure 1.

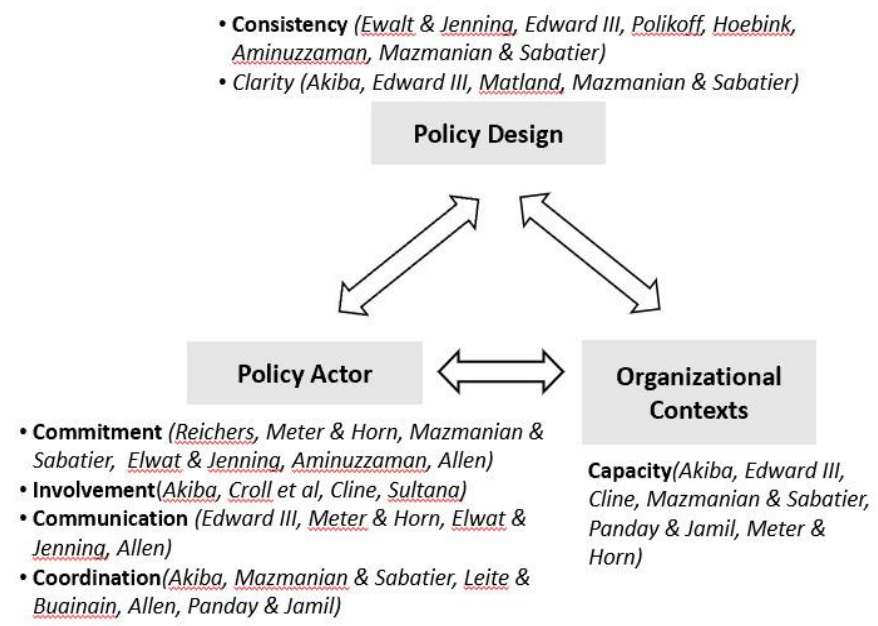

\section{Research Method}

Figure 1. Research Framework

The post positivism paradigm in this research is carried out using the implementation policy feedback relationship proposed by Akiba (2013) and system-based thinking. Research analysis uses methodology stage of the dynamic system delivered by Maani and Cavana (2000). The stage of methodology stage is simplified based on research needs as shown in Figure 2.

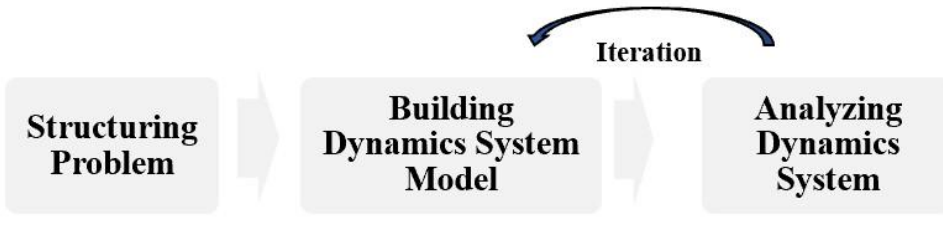

Figure 2. Stages of Dynamic System Research

Source :Maani and Cavana, 2000 (Modification)

The first stage is the preparation and structuring of the problem. The initial steps begin with identification of problems or related issues to the teacher distribution policy implementation. The identification is carried out through documents including teacher regulations, report documents, and teachers research to obtain preliminary data and information.

Building a system dynamics model as second stage based on the identification of variables, concepts and theories and empirical data. Variables, concepts and theories was obtained from research studies. Empirical data includes information of regional policy teacher distribution was obtained from documents in the library, institutional support and internet. Other data was also obtained from observations, interviews and instruments. Researcher and respondents face to face to obtain direct information. 
The researcher submits questions to the respondent, stimulate the respondent to answer them, explore further answers and record the interview result. Interviews with high level central and regional officer who was policy makers and implementers were selected using the purposeful sampling method.

Based on data and information, Causal loop diagram (CLD) was developed to articulate the empirical problem in the field. CLD was an expression of the events of feedback relationships into particular picture language. CLD must passed two testing step namely structure verification validation and output validation. The aim of verification structure validation to compare the model that has been formed with the real world using the existing interviews result or conducting further interviews. This was done to ensure that the model was in accordance with the conditions on the ground. Model validated using interview result with educational experts, education practitioners and professional organizations.

Output validation using forecasting was generated through simulation models to calculate the accuracy of forecasting behaviour with real conditions when the structure model was built. For that aim, this research using Mean Absolute Percentage Error / MAPE, with a maximum range of 10\% (Chui, 2008). Real condition data collected from 118 respondents who was implementers regional level in 104 areas using convenience sampling techniques.

\section{Result and Discussion}

\subsection{Implementation of Teacher Distribution Policy}

\subsubsection{Policy Design}

Teacher distribution is an instrument structuring and equity of teacher that is conducted by the central and regional governments by considering teacher equality inter-levels and status of schools, inter-districts and inter-provinces. The first step in the distribution is to calculate the teacher needs to obtain a map of teacher supply in one area. Calculation of teacher needs requires information regarding (1) the number of participants in education, (2) the number of study groups, (3) allocation of time for each student and curriculum structure and (4) face-to-face workload. The teacher need analysis is performed gradually from teacher need calculation from schools to districts, provinces and national levels. The analysis can describe the distribution of teachers along with the excess/shortage map of teachers. The regional government can take one of the actions in teacher structuring (that is, recruitment or distribution) based on teacher needs analysis.

Teacher distribution policies involve all education elements from the central government, regional government, the community and teachers. The teacher distribution policy is also related to other regulations on staffing, employment, finance and regional government. A strategy to overcome teacher distribution in the broad teacher policy sphere is the issuance of 2011 Joint Decree of 5 Ministerial on the Structuring and Distribution of Civil Service Teachers (PNS). During implement, the regulation is insufficient when dealt by regional government. Some stakeholders, particularly in the regions, notice the decree undermining autonomy and the design that does not account for the differences in budgeting political interests between the central and regional governments (ICW, 2015).

- Clarity

The first step of teacher distribution is teacher needs analysis. Essentially, the formula of teacher need calculation is the same in every level. Still, a high level of school indicates highly complex formulation of teacher need analysis. In this part, the formula of teacher need calculation is technically difficult to operationalise.

Another problem in teacher need analysis is the difference in data updates and understanding of the variables used. The differences in understanding, data and variables generate differences in results of teacher need analysis between central and regional institutions.

- Consistency

Various other policies are related to teacher distribution policies. National and regional curriculum which are the components in teacher need analysis; regional finance policies, education management authority; and government employment policies. Overlapping policies must avoid to not make hesitation and confusion of implementers on the field.

\subsubsection{Policy Actors}

Policymaker, implementers, facilitators and policy mediators are roles that can be presented by education government institutions, teachers, teacher associations and the community. Each of these groups can have more than one role (Akiba, 2013). In this study, the actors discussed are MOEC as policy maker and regional governments and schools as implementers. 
- Involvement

Dye (2013) defined public policy as whatever governments choose to do or not to do. In the context of teacher distribution policy, the option of not doing anything emerges when the regional government is irresponsible in dealing with teacher equity. When the regional government cannot show any actions in dealing with uneven distribution, the school initiates to meet the school needs. The initiative leads to a new problem of the growing number of contract teachers who can burden civil servant teachers to fulfil a minimum of $24 \mathrm{~h}$ teaching obligation.

- Commitment

Commitment becomes the solemnity of the implementer in the implementation of teacher distribution policy. Such commitment can be viewed from the learning and digestion of policies by the actors. Commitments are also viewed from the willingness of actors to implement policy strategies; one of them generates regional teacher distribution regulation as law basis that must be complied by all stakeholders in the region. The MOEC reported that only a small number of regions have regional regulations. Actor commitments reduce resistance and thus enable complete acceptance of teacher distribution policies. In this position, the role of the regional government becomes as important as a mentor and mediator during the process in reducing the prejudice of teacher distribution policies with likes and dislikes.

- Communication

Communication has been carried out well by all parties starting from central to regional. Since the issuance of 2011 Joint Decree of 5 Ministerial, massive communications has been carried out to the regional government, especially the district education office and Regional Personnel Agency (BKD). The objective was to open up regional insights into teacher structuring and distribution. Thereafter, technical guidance and mentoring were held to regions. Same step was carried out by foreign donor agencies. Even foreign donors continued to mentor the teacher distribution process until it was fully implemented.

- Coordination

Coordination related to teacher distribution policies is held between vertical and horizontal offices. Regional horizontal coordination is between the district education offices and the BKD as the authorised agency in administering civil servant teachers. Regional vertical coordination is between the district education agency and schools to obtain a schoollevel teacher shortage/excess map, which will be aggregated at the district level. Other vertical coordination was implemented annually in the period of 2011-2015 by MOEC, district education agency and BKD.

The coordination has been carried out through workshops and mentoring. The material of the workshop covers information for the implementer on the importance of teacher distribution policy and how to perform it. Mentoring is a further step to provide the regional government with reinforcement for implementing the strategy of teacher distribution. Only a small number of regions can continue the next phase of the coordination, that is issuance of teacher distribution regional regulations.

\subsubsection{Organisation}

The organisational context observed includes organisational capacity in providing data, funding and management, organisational structure and human resources. Four factors greatly influence the implementation of teacher distribution policy.

- Data Availability

Data availability is used to calculate teacher needs. MOEC has Education Basic Data (EBD) as a system for managing integrated education data to support integrated data availability and information. Data collection in EBD comprises three education data entities, namely, student, education units and educators. EBD is expected to be a valid data source that can be utilised by all education elements from central and regional institutions. Unfortunately, EBD cannot be utilised maximally by the district education agencies. Education agencies find some difficulties to access EBD. As a result, data used in analysing teacher needs are not optimised. Ultimately, education agencies have weak arguments in conducting teacher distribution and are easily refuted by other interest parties.

- Funds and Management

The fund is a resource that drives the implementation of teacher distribution policy. The process of transferring teachers can run smoothly with offers transfer funds to teachers and families. Special allowances should be provided to teachers when they are transferred to certain areas. Major financial support results in a situation in which only the area with a solid financial service can carry out the teacher distribution policy properly. 
- Human Resource Capacity

Adequate human resources, such as sufficient numbers and skills, are important in conducting teacher distribution policy. The ability or capacity of staff members in managing and analysing data helps them create useful analysis for leaders in designing appropriate teacher distribution policy. At the moment, capacity building effort is still often constrained due the frequent changes of human resource managers. Frequent regional government shift needs transition of perception for the new teacher management responsibility. Moreover, some continuous workshops are sometimes attended by different people for each meeting. As a result, the information obtained is not intact.

- Organisational Structure

The district education office becomes a regional agency that implements teacher distribution policies. The teacher distribution policy stage is largely stopped at the stage of teacher need analysis. The next stage of providing teacher regional distribution regulation is not done by resistance factors, funding factors and ignorance. As stated earlier, ignorance occurs because of frequent changes in human resource managers that cause a small amount of information received.

The enactment of Law No. 23 of 2014 on The Regional Government alter the implementation of teacher distribution policy. Important alterations are performed by the teacher distribution management authority in central areas, provinces and districts. The central office conducts national administration. The provincial office conducts high school teacher management, and the district office conducts primary education teacher management. The regulation issuance also caused significant organisational alteration in the province and district levels in 2017.

\subsection{Dynamic System of Teacher Distribution Policy Implementation}

The dynamic model of implementation is established by identifying variables from concept and theory models, exploring empirical data with interviews and questionnaires and drawing CLDs (Maani and Cavana, 2000). The model of teacher distribution policy is based on the model of the teacher policy reform established by Akiba in 2013 with its three dimensions: policy design, actors and organisational contexts. On the basis of theoretical review and field verification, seven stock variables and twelve indicators are established with their interactions, dependencies and causal relationships due to the implementation of teacher distribution policy.

All variables are interacting, relating, interdependent and united in a system. The dynamic interactions in the implementation of teacher distribution policy form a large and complex system, which is drawn in the CLD model. The CLD model answers and explains the interactivity systemic ability from the implementation of teacher distribution policy. Figure 3 shows an empirical model for developing the Akiba conceptual model (2013). This model has been verified on the basis of field information and becomes the model of Indonesia teacher distribution policy implementation in regional level. Figure 4 shows the output diagram of the computation model of Indonesia teacher distribution policy implementation in regional level obtained by entering the quantity data questionnaire and secondary data.

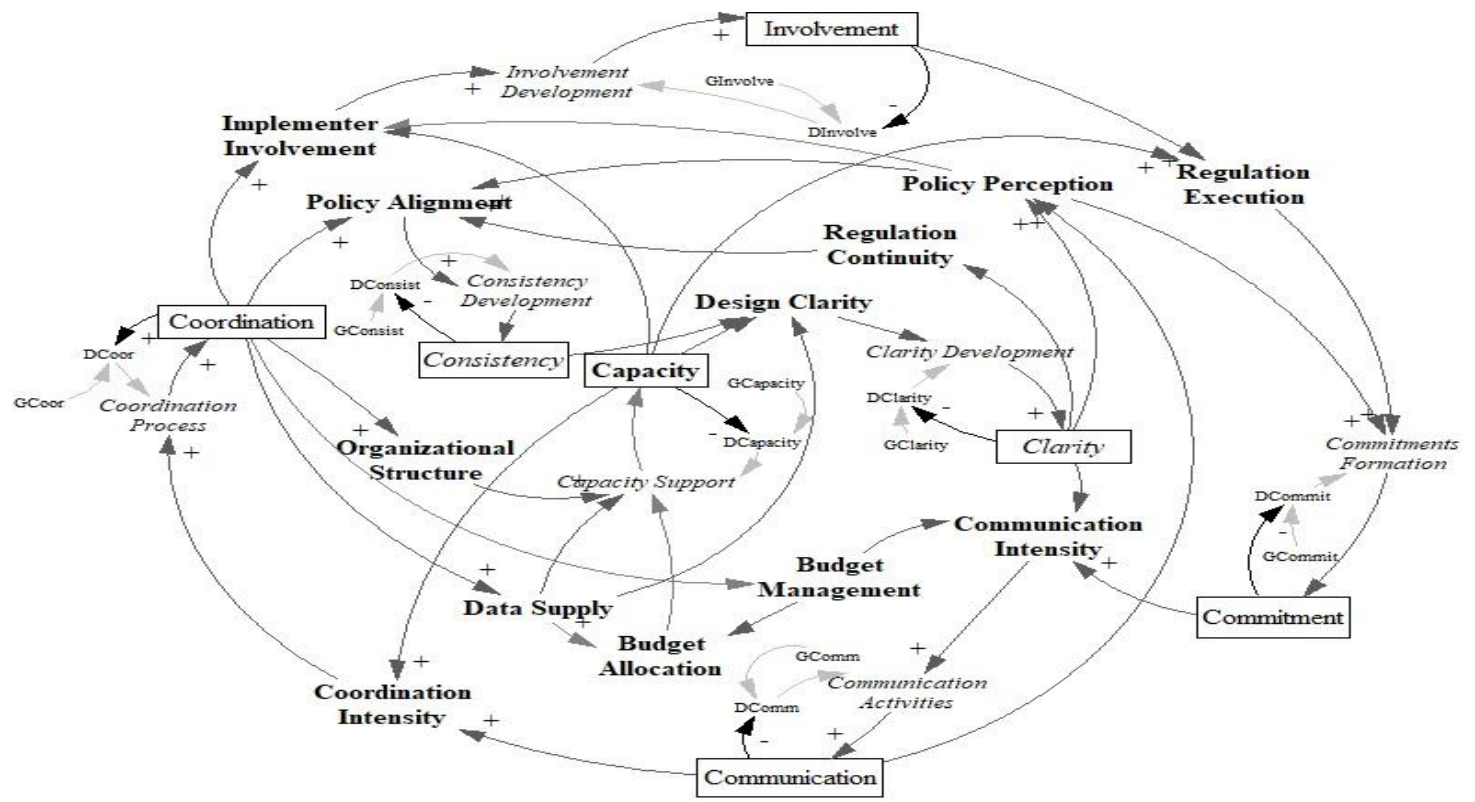

Figure 3. Model of Teacher Distribution Policy Implementation 
In general, the dynamic model implies a goal seeking pattern. This pattern shows that facile acceleration in the initial stage is becomes increasingly difficult until achievement of the goal. At the initial stage, accelerates because the actor has been directly adapted and moves to convey knowledge or do improvement actions or both. The acceleration phase can be observed in the graph, during which significant changes are found in all observed stock variable. This acceleration phase occurs amidst euphoria and high expectation over teacher distribution policy. The graphs show that this phase lasts for 7 years. On the eighth year, a deceleration process occurs in the system. The latest stage is a stable, a situation in which all needed knowledge has been already known, capacity has been fulfilled and good steps have been practiced.

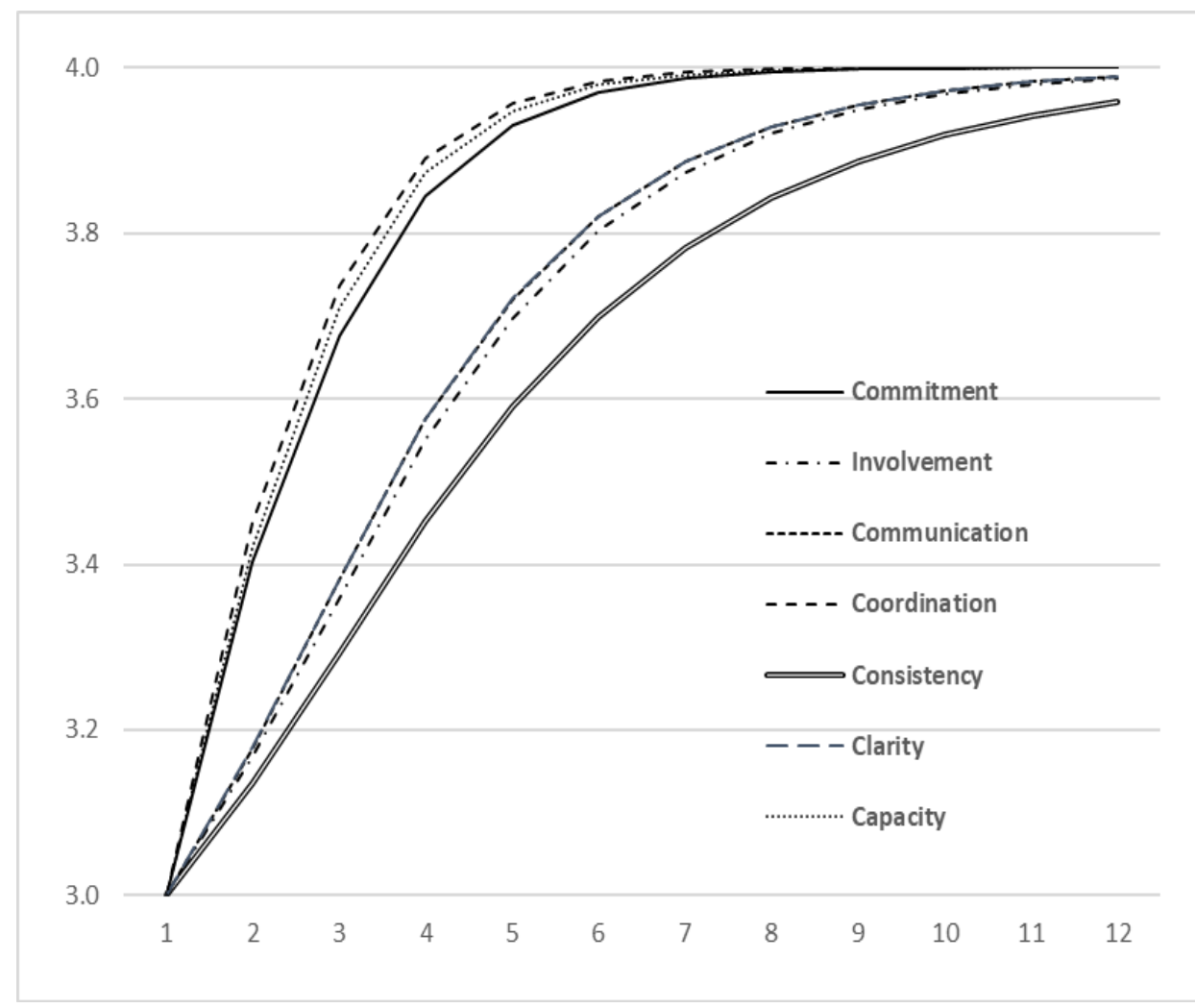

Figure 4. Output of Computing Result Model of Teacher Distribution Policy Implementation

The goal seeking pattern appears because the stock variable produces loop balancing. The system dynamic model aims to obtain a better value equivalent 4 number for the stock variable. The limit to this value in goal seeking approach for policy efficiency can fail in the multilevel governance system (Charbit, 2011).

The challenge for the multilevel governance system such as decentralise teacher management comprises information distortion and capacity, financial, policy, accountability and objective gaps. These gaps result in balancing and limiting values for each stock variable.

Information distortion reduces communication effectiveness (Edward III, 1980). Information distortion occurs because of the differences in actors who obtain socialisation and implementers without accompaniment of adequate knowledge transfer. Furthermore, information gaps occur due to the massive communication and coordination that is not followed by mentoring.

The issue of imposed group interest is also a source of balancing in the model structure. The reason is that many findings of the distribution of teachers are not based on teacher need analysis but become part of punishment and reward as regional level election support.

Another balancing source is personal interest that leads to ignorance. Foreign donors provide assistance to regional governments by coordinating, improving human resource competencies and mentoring for implementing teacher distribution policies. When foreign donors provide complete assistance, many regions stop implementing policies. Only few regions will carry out policies because their district leadership still have interest to continue them. Program unsustainability occurs due to that many districts have problems with budget constraints, which require setting up priority programs. Unfortunately, teacher distribution policy is not a district priority program in many areas. 
When the implementation model is applied, perceptible and implementable policy designs can increase communication effectiveness and reduce information distortion. This application can also affect the effectiveness of actor policy interactions. Ultimately, the interaction effectiveness increases the involvement of actors and their commitment in implementing policies. This actor interaction occurs continuously by providing proposals for improving policy designs by making them clearer and more accurate than before to achieve the objectives of the policy.

The real interaction can be observed from the analysis of the distribution based on teacher needs. The teacher need analysis is a workload analysis formula that comprises student number, study group and curriculum structure. The instrument for teacher needs analysis must be perceptible and useful and produce appropriate results that match the field conditions. If the formula is easy to understand and use, then the policymaker can easily convey the formula to the implementer. On the basis of the analysis, the regional governments can obtain strong materials for discussion with other actors (that is, teachers and schools). The compatibility of analysis with the field is the organisational strength to perform teacher distribution policy.

The model also shows that actor interaction can affect the optimisation of organisational capacity in implementing teacher distribution policies. The results of district actor interaction increase organisational capacity, that is, the authority organisational structure to handle teacher distribution and the issuance of the regional teacher distribution regulation; human resource competency improvement; data and information systems as inputs in analysing teacher needs; mobilisation funding support and additional incentive for transferred teachers. The organisational capacity support becomes feedback in improving the policy actor interaction quality and as an input to the policy redesign based on the current organisational capacity information.

The opportunity for the actor to be involved and committed to implement the policy will increase when the policy is properly addressed and policy design is appropriately achieved for the policy objectives. The choice to involve in policy implementation with high can be seen from the issuance of regional regulations on the distribution of teachers.

Regional governments also continue to obtain companion in implementing policies in the regional. The companion process is performed to increase involvement and commitment of regional actors in implementing policies. The process is conducted through organisational element optimisation to maximise the organisational capacity. The regional government is escorted in preparing teacher data, guided in doing teacher need analysis and accompanied in coordinating to obtain support from various agencies with interest in teacher distribution policy.

The model shows that the processes that occurred in various organisational elements become a learning process for policy actors. The difficulty of the funding to issue regional regulations, the difference in understanding teacher need calculation formula, the number of resistances from teachers and schools and the lack of financing support become lessons to learn for actors and inputs for policy design. On the basis of the inputs, policy design can be improved by making it clearer and more appropriate than before to be accepted and implemented in the field.

The dynamic model of distribution policy implementation in Indonesia does not show a direct correlation between policy design and organizational context as stated by Akiba (2013). The designed policies have failed to increase the organisational capacity directly. The policy design can affect organisational capacity indirectly by presenting actors as the agent. The actors become the connector, thereby making policy design the driving force that moves organisational capacity.

In the context of teacher distribution policies, policy design includes the need for regional teacher distribution regulations and analysis of teacher needs. Both can change organizational capacity through changes in organizational structure, technical guidance for managers, financial support, and the regional data collection information systems. However, changes in organizational capacity cannot be immediate, there needs to be encouragement by the interaction of communication and coordination between teacher distribution policy actors both at central and regional levels.

\section{Conclusion}

The dynamic of model implementing teacher distribution policies in regional level shows that was the slowdown occurred in the form of budget constraints in the regional level funds management and information distortion. In addition, empirical shows the occurrence of personal interests and sectoral egos of actors and regional governments in determining regional priority programs. Interdependent relationships occur between actors and design and between actors and capacities. However, relationship between design and organizational context occurs in one direction. There is no direct relationship from design to the organizational context marks neglect of the role of organizational context when formulating the policy. The policy design process does not pay attention to the availability of organisational capacity. Central and regional governments do not rapidly prepare various organisational contexts that can support policies that have been designed. That resulted in the slow achievement of policy objectives. 
The distribution teacher policy can be rapidly achieved by giving attention to the harmony between the policy design and the capacity development of organisational elements by ensuring adequate organisational structure for serving policies, human resources in management and funds. The harmony can be achieved by a large number of coordination and communication from various factors involved, thereby providing valid information about the capacity of organisational elements.

\section{References}

Akiba, Motoko (2013). Teacher Reforms Around the World, Implementations and Outcomes. UK:Emerald Group Publishing Limited.

Akiba, M. (2017). Editor's Introduction: Understanding Cross-National Differences in Globalized Teacher Reforms. Educational Researcher, Vol. 46 No. 4:153-168.https://doi.org/10.3102/0013189X17711908

Annor, S. and Allen, P. (2008), "Why is it difficult to promote public mental health? A study of policy implementation at local level", Journal of Public Mental Health, Vol. 7 No. 4, pp. 17-29. https://doi.org/10.1108/17465729200800025

Atmoko, Andreo W. (2009). Dinamika Knowing Organization di Perusahaan Konsultan SDM: Studi Kasus Daya Dimensi Indonesia. Dissertation, University of Indonesia, Jakarta.

Chui-Yen, Chen and Chin-Min. (2008). A Study of Forecasting for the Cross-Straits Trade. WSEAS Transaction on Business and Ecnomics. Issue 5, Volume 5, May 2008

Chang, Mae Chu, Sheldon Shaeffer, Samer Al-Samarrai, Andrew B. Ragatz, Joppe de Ree, and Ritchie Stevenson. (2014). Teacher Reform in Indonesia: The Role of Politics and Evidence in Policy Making. Directions in Development. Washington, DC: World Bank.

Charbit, C. (2011). Governance of Public Policies in Decentralised Contexts: The Multi-level Approach. OECD Regional Development Working Papers, 2011/04. OECD Publishing."

Cline, Kurt D. (2003). Influences on Intergovernmental Implementation: The States and the Superfund. State Politics and Policy Quarterly, Vol. 3, No. 1 (Spring, 2003) : 66-83

Croll, Paul and Abbott, Dorothy and Broadfoot, Patricia and Osborn, Marilyn and Pollard, A. (2010). Teachers and Education Policy: Roles and Models. British Journal of Educational Studies. 42:333-347.

Dye, Thomas R. (2013). Understanding public policy 14th ed. NJ: Pearson Education, Inc. Upper Saddle River.

Edward III, George C. (1980). Implementing Public Policy. Washington D.C. : Congressional Quarterly Inc.

Ewalt , Jo Ann G., Edward T. Jennings and Jr. (2004) Administration, Governance, and Policy Tools in Welfare Policy Implementation. Public Administration Review, Vol. 64, No. 4 (Jul. - Aug., 2004): 449-462

Flood, Robert L. and Michael C. Jackson. 1991. Creative Problem Solving: Total Systems Intervention. West Sussex England : John Wiley and Sons Ltd.

Goggin, Malcolm L . 1986. The "Too Few Cases/Too Many Variables" Problem In Implementation Research. Political Research Quarterly 1986 39: 328-347

Hill, Michael and Peter Hupe. 2002. Implementing Public Policy: Governance in Theory and in Practice. London:, SAGE Publications.

Hoebink, Paul. (2004). Coherence And Development Policy - An Autopsy And Some European Examples. EUEntwicklungspolitik Quo vadis?: OFSE, pp 37-50.

Honig, M.I. (2006). New directions in education policy implementation: Confronting complexity Albany, NY: State University of New York Press.

ICW. (2015) Kegagalan Pemerataan Guru, Evaluasi SKB 5 Menteri Tahun 2011 Tentang Penataan Dan Pemerataan Guru PNS di Indonesia. Jakarta: Indonesia Corruption Watch.

Jackson, Michael C.. 2003. Systems Thinking: Creative Holism for Managers. West Sussex England: John Wiley and Sons Ltd.

Leite. Juliana Pires de Arrudadan Antonio Márcio Buainain 2013 Organizational Coordination in Public Policy Implementation: Practical Dimensions and Conceptual Elements Central European Journal of Public Policy Vol. 7 - № 2 - December 2013:136-159.

Maani, Kambiz E., (2000). Systems Thinking and Modelling: Understanding Change and Complexity. Auckland, New Zealand: Pearson Education

Matland, Richard E.(1995). Synthesizing the Implementation Literature: The Ambiguity-Conflict Model of Policy Implementation. Journal of Public Administration Research and Theory: J-PART, Vol. 5, No. 2(Apr., 1995):145-174

Panday, Pranab Kumar and Ishtiaq Jamil. 2010. Challenges of Coordination in Implementing Urban Policy: The Bangladesh Experience. Public Organiz Rev (2011) 11:155-176 
Polikoff, Morgan S. (2012). The Association of State Policy Attributes With Teachers' Instructional Alignment. Educational Evaluation and Policy Analysis. Month XXXX, Vol. XX, No. X: 1-17

Sabatier, P.A, and Mazmanian, D. (1980). The Implementation Of Public Policy ; A Framework Of Analysis, Policy Studies Journal, Vol. 8, January 1980:538-560

Hutagalung, Simon Sumanjoyo. (2018).Tata Kelola Akselerasi Penyelenggaraan Pendidikan Pada Kabupaten Pesisir Barat Provinsi Lampung. Sosiohumaniora - Jurna IIlmu-ilmu Sosial dan Humaniora Vol. 20, No. 3, Nopember 2018: 236 - 244

Samarrai, Samer Al; Syukriyah, Daim; Setiawan, Imam. 2012. Making better use of teachers : strengthening teacher management to improve the efficiency and equity of public spending (English). Policy brief. Washington DC : World Bank.. http://documents.worldbank.org/curated/en/602311468038719842/Making-better-use-ofteachers-strengthening-teacher-management-to-improve-the-efficiency-and-equity-of-public-spending

Smith, T. B. (1973). "The Policy Implementation Process," Policy Sciences 4, 2 (June 1973): 197-209.

Sultana, Ronald G. (2008) The Challenge Of Policy Implementation: A Comparative Analysis Of Vocational School Reforms In Albania, Kosovo And Turkey. European Training Foundation.

USAID-KINERJA. 2014 Tata Kelola Distribusi Guru Secara Proporsional (DGP) Seri Pembelajaran dari USAIDKINERJA. www.kinerja.or.id

Van Meter, Donald S. and Carl E. Van Horn (1975), "The Policy Implementation Process: A Conceptual Framework". Administration and Society, Vol.6, No.4:445-488. 